\title{
Defining Requirements for Improved Photovoltaic System Reliability
}

\author{
Alexander Maish*
}

Photovoltaic System Applications Department, Sandia National Laboratories, Albuquerque, New Maxina Fin

\section{SUMMARY}

JAN 211999

Reliable systems are an essential ingredient of any technology progressing toward commercial maturity and large-scale deployment. This paper defines reliability as meeting system functional requirements, and then develops a framework to understand and quantify photovoltaic (PV) system reliability based on initial and ongoing costs and system value. The core elements necessary to achieve reliable PV systems are reviewed. These include appropriate system design, satisfactory component reliability, and proper installation and servicing. Reliability status, key issues, and present needs in system reliability are summarized for four application sectors.

\section{INTRODUCTION}

Reliable systems are an essential ingredient of any technology progressing toward commercial maturity and large-scale deployment. Consensus emerged at a recent photovoltaic (PV) industry forum that PV systems' reputation as not being too reliable is hurting market penetration. ${ }^{1}$ The forum concluded that purchasers need to be better educated to purchase lowest cost warranted systems rather than lowest capital cost systems. But having better quantified system-level reliability data is also important for system design and project cost estimation and approval.

Reliability encompasses a wide range of concepts and issues, and it touches all phases of a PV project. How do we start structuring an approach to deal with these various aspects of reliability? How do we define reliability and how do we quantify it? How do we determine what needs to be known and what needs to be done to improve system reliability? What is the status of PV system reliability? What is known and what information is needed? This paper accomplishes the following:

- Develops a framework to understand and quantify PV system reliability.

- Identifies core elements necessary for achieving reliable PV systems.

- Summarizes the reliability status, key issues, and needs of PV systems by application sector.

\footnotetext{
*Correspondence to: Alexander Maish, Sandia National Laboratories, P. O. Box 5800, Albuquerque, NM 87185-0753. E-mail: abmaish@sandia.gov, www.sandia.gov/pv

Sandia is a multi-program laboratory operated by Sandia Corporation, a Lockheed Martin Company, for the U.S. Department of Energy under contract DE-AC04-94AL8500.
} 


\section{DISCLAIMER}

This report was prepared as an account of work sponsored by an agency of the United States Government. Neither the United States Government nor any agency thereof, nor any of their employees, make any warranty, express or implied, or assumes any legal liability or responsibility for the accuracy, completeness, or usefulness of any information, apparatus, product, or process disclosed, or represents that its use would not infringe privately owned rights. Reference herein to any specific commercial product, process, or service by trade name, trademark, manufacturer, or otherwise does not necessarily constitute or imply its endorsement, recommendation, or favoring by the United States Government or any agency thereof. The views and opinions of authors expressed herein do not necessarily state or reflect those of the United States Government or any agency thereof. 


\section{DISCLAIMER}

Portions of this document may be illegible in electronic image products. Images are produced from the best available original document. 


\section{Developing a Framework to Evaluate System Reliability}

A program to improve PV system reliability must identify and address key issues. This implies understanding what reliability is and what issues fall into the scope of a reliability program. It also implies a metric to measure and rank reliability issues. This section develops the framework to accomplish this task.

The first step is to define reliability in the context of PV systems. In this effort, a reliable system is defined as one that works as expected. This requires that one identify the functional requirements for the system. Examples of system functional requirements are providing a specified level of lighting for a certain time period, delivering an amount of water to a tank in a given period, and delivering an amount of electrical energy to the grid often within a time window. Notice that the functional requirements are defined as delivery of a service, which requires that the scope of the system include the load. This is true even for grid-tied systems if one considers the grid load requirements as an aggregate, for example, mitigating the grid peaking load requirements or providing line extension load support. Inclusion of the load in the system is important because optimization of the overall system is often achieved, at least in part, by mitigation of the load. Additionally it is often necessary to modify the load to be compatible with the characteristics of the remainder of the PV system.

It is important to realize that the reliability of the system, i.e., its ability to meet its functional requirements, is not necessarily the same as the reliability of the system components. A system can be designed to tolerate failure of components without failure of the system. This is often accomplished with redundancy. An example is an area lighting system with dual lamps. Alternatively, a poorly designed or installed system can fail even though the components operate as designed. This can occur, for example, in a lighting system with poor quality lights that do not meet the customer's needs. It is also important to realize that the optimum operation of the system may require components to operate differently than if their performance were optimized independently. For example, the optimum operating scenario for a hybrid system (one with both a PV and an engine generator) may require less frequent charging of the batteries to reduce low-load engine operation, whereas individually, the battery life is optimized by regular full charges.

The many different facets of reliability, such as component failures, degradation, scheduled and unscheduled maintenance, and equipment wear-out must all be put on a common quantitative basis before one can make decisions of relative importance and attempt to optimize the system. Component and system reliability can be quantified by measures such as mean time between failure (MTBF), mean time to repair (MTTR), and availability. Although important for understanding aspects of reliability, these are intermediate metrics. The ultimate metric that is common to all aspect of reliability is cost.

The equation that relates costs for PV systems is the viability/sustainability (VS) (equation 1) which is used to determine both initial system viability and system ongoing sustainability. Minimizing the cost side of this equation as an aggregate and maximizing the value side optimizes system design. The difference is profit or return on investment (ROI), which must be positive for the system to be sustainable. One caveat to this optimization process is that funds for actual costs must be available to the payer for the appropriate category of expense. In some government projects, for example, funds for capital expenses are more readily available than funds for ongoing operation and maintenance (O\&M) expenses, leading to a design optimum that does not minimize overall costs but instead minimizes costs in certain expense categories. If funds are not available to pay expenses-- 
even if there are sufficient indirect values to satisfy the equation--the system will not be sustainable. In the VS equation, costs that occur at different times must be adjusted for the time-value of money to a common reference, normally present value when determining system viability, and levelized over time when determining sustainability. As we will see, reliability costs can contribute to multiple categories in this equation, not just the commonly expected operation and maintenance (O\&M) category. Thus reliability must be evaluated by considering all these categories rather than just minimizing system O\&M.

$$
\text { Capital + Capital Replacement }+ \text { O\&M + Disposal }<\text { Value }
$$

Capital = Up front costs including design, project management, installation, equipment costs, etc. Reliability contributions would include the extra cost of hardware selected to avoid O\&M costs when maintenance is expensive. (Example: more expensive valve regulated lead acid (VRLA) batteries selected to avoid frequent watering requirements of flooded lead acid batteries.)

Capital Replacement $=$ Component replacement cost including hardware cost, direct and indirect labor. This category generally applies to major hardware that wears out, such as batteries or power electronics. Reliability contributions would include the cost of more frequent replacements of hardware used to lower equipment cost. (Example: Frequent replacement of SLI (automotive) batteries as an alternative to longer lasting but more expensive deep discharge batteries.)

O\&M = Operation costs, site personnel, scheduled and unscheduled maintenance, hardware and labor costs, etc. Reliability contributions can include more frequent scheduled or unscheduled maintenance in low cost O\&M applications to offset more reliable but more expensive equipment.

Disposal $=$ Cost of system removal and disposal less its salvage value.

Value $=$ Direct and indirect benefits of the system. Quantifying value is often difficult. Value is often backed into by determining the avoided direct costs of displaced or alternative energy sources (grid supplied or diesel generated electricity), or the avoided indirect cost of not having service (loss of livestock from not having water, emissions and noise from alternative power generation, loss of opportunity such as afforded by domestic lighting, cost of line extension, or potential national economic security losses from disruption of fossil energy supplies). Reliability contributions include reduced outages and degradation resulting in higher system output and value.

The equation applies separately for each individual payer connected with a project. A payer but who does not receive direct value from the service but who provides a buy-down or tax break to reduce the capital cost must receive an indirect value sufficient to justify the expense. The beneficiary of such a buy-down sees a reduced cost side of the equation, improving the likelihood that the remaining costs are less than the ongoing value.

This equation also makes it clear why it is imperative that all the costs remain linked in the optimization process. A system optimized to respond to a bid specifying lowest capital cost will likely have excessive $O \& M$ and capital replacement costs, providing non-optimal overall costs. By purchasing value (energy), or by specifying extended system warrantees or long-term performance guarantees, a purchase agreement can ensure that O\&M costs remain coupled to the capital costs, improving the likelihood of optimizing overall costs. 
The VS equation sets an upper limit on allowable O\&M expenses. Non-critical (low value) systems, such as grid-tied systems or small area lighting systems, may be left unserviced until it is economical to do so, such as during scheduled maintenance or when a number of service calls can be aggregated to reduce the individual cost. Alternatively, high-criticality (highvalue) systems, such as remote telecommunication relays, may warrant pre-emptive scheduled maintenance or a remote data acquisition system (DAS) to anticipate outages.

We are now ready to answer the question of whether low performance and degradation are reliability issues. Performance and degradation impact system value; and while it is important to ensure satisfactory system operation upon installation and at regular intervals using qualification tests, low performance and degradation become reliability issues only when the system fails to meet its functional requirements and requires O\&M or capital replacement expenses. Systems can be oversized in anticipation of normal degradation or low performance to ensure achieving functional requirements, and the system is still considered reliable.

A program to improve PV system reliability identifies and addresses key issues affecting system viability and sustainability resulting from costs to ensure the system meets its functional requirements and from reduced value due to degradation of service. This requires not only quantitative knowledge of the long term reliability performance of the system, including failure rates, maintenance, capital replacement, degradation, and end-of-life failure modes, but also an understanding of the available reliability tradeoffs and how they impact system value and costs in all categories. For example, an understanding of the critical impact of maintenance in certain battery storage systems on the battery capital replacement cost can lead to sustainable projects that ensure this maintenance is performed.

\section{Core Elements of Reliable Photovoltaic Systems}

The previous section introduced the methodology for identifying key reliability issues based on cost metrics and the viability/sustainability equation. Key issues are those that have the greatest impact on system viability and sustainability. This section introduces the generic core elements required to achieve reliable PV systems, and the next section evaluates the status of PV technology relative to these core elements and identifies the key reliability issues for each application sector.

The most important element necessary for achieving reliable systems is the system design. It must be appropriate for the solar resource, the load, the local servicing infrastructure, and the capabilities and needs of the user. To achieve a reliable system the designer must understand the operation and interaction of system components under the varying solar resources at the system installation site and under the application load conditions. This may require custom sizing of components for a given project or selection of the appropriate package from a pre-designed family of designs. This is especially true for systems involving battery storage. A reliable design also requires selection of the appropriate components for the application, local servicing infrastructure, and cost. Maintenance considerations often drive this aspect of the design, especially when there are a range of options with varying maintenance requirements such as for batteries. To achieve error-free installation and servicing, the design must be user-friendly and appropriate to the skill level of the installer/servicer. 
The second element necessary for achieving reliable systems is having adequate component reliability. This requires not only a quality component design, which can be evaluated using appropriate standards, accelerated stress tests, qualification tests, and listing tests, but also appropriate manufacturing and shipping, which requires ongoing adherence to quality standards such as ISO-9001. Inferior component reliability may require design strategies such as redundancy, or increased maintenance or capital replacement to achieve adequate system reliability.

The final element is achieving quality installation and maintenance. This is more than an event: it is a process requiring development of training materials and methods, identification and/or implementation of local servicing infrastructures, and development of testing procedures, all appropriate to the design's complexity.

All of these elements combined require a great degree of systems design experience, which draws on lessons learned from previously installed systems and research efforts. A methodology to consolidate this information into recommended design and operation guidelines can provide a common resource for system integrators and operators, improving system reliability.

\section{Status and Key Issues Facing PV System Reliability}

PV systems developed for different application categories have different functions, employ different components, and face different issues. The first step is to divide the range of PV systems into major application sectors. The core reliability elements (design, component reliability, and installation/servicing) for each application sector is then evaluated to identify status, key issues, and recommendations for future activities.

Four application sectors were identified, roughly corresponding to small and large, gridtied, and remote applications. Small grid-tied systems include residential and commercial applications normally ranging from $1-100 \mathrm{~kW}$. These are generally fixed building-mounted systems. Larger grid-tied systems providing bulk power directly to the grid are generally ground-mounted tracking systems. These range from $100 \mathrm{~kW}$ to multi-megawatt in size. Remote power systems are divided into hybrid systems, which use an alternate power system besides the PV panels to serve residential and institutional loads in the $2-200 \mathrm{~kW}$ range, and non-hybrid systems, which rely solely on PV and are generally smaller ( $10 \mathrm{~W}$ to $5 \mathrm{~kW})$. Nonhybrid remote systems include direct power applications that do not store electrical energy, such as water pumping, and applications that do include battery storage, such as domestic and area lighting, smaller telecommunication relays, and cathodic protection.

\section{Status and Key Reliability Issues for Grid-tied Residential and Commercial Systems}

Grid-tied residential and commercial systems are seeing increasing emphasis from nationallysponsored solar roof programs in several countries (Japan, Italy, the United States, etc.), and from other programs such as the Sacramento Municipal Utility District's (SMUD) PV Pioneer green pricing program and the Utility Photovoltaic Group's (UPVG) TEAM-UP program. Although most designs use crystalline modules mounted on rooftops, new designs are emerging that leverage the existing structure, integrate with the building, or provide additional 
value. United Solar System Corporation's (USSC) flexible triple junction amorphous product is designed for new construction or, soon, as an add-on to metal roofing panels. ${ }^{2}$ Powerlight markets a product mounted on proven roofing insulation panels that requires no, or few, roof penetrations. ${ }^{3}$ Several companies are moving into the building integrated market with panels that serve as architectural glass. The functional requirement of these systems is to provide electrical energy to the grid, generally offsetting peaking demands. Although externalities such as green pricing and emissions allowances can raise the value of the produced energy somewhat, the viability of any grid-tied PV system is made difficult by the low value of the energy produced. This ranges between $2-10 \notin / \mathrm{kWh}$ depending on whether the wholesale or retail cost of energy is used. A target for O\&M costs needs to be low, probably below $1 \mathrm{c} / \mathrm{kWh}$, leaving most of the value to recoup the system capital cost. At this rate, the persystem allowable annual O\&M for systems between 2 and $100 \mathrm{~kW}$ ranges from $\$ 37$ to $\$ 1825$.

Grid-tied residential and commercial system design is straightforward and is not a reliability issue if properly executed. This requires complying with applicable codes including the National Electrical Code (NEC); minimizing site assembly and the chance of incorrect assembly by pre-assembling dc circuit components into a listed source circuit protector box; and developing standardized designs to resolve design issues, minimize inventory, and simplify service technician training.

Component reliability, on the other hand, has been a significant issue, especially with inverters. This appears to be a temporary condition that is being resolved as present PV inverter manufacturers, whose experience has largely been with the remote market, develop maturity in the grid-tied market and modify their products to be more tolerant of the more demanding line disturbances that exist on the grid. Development of UL1741 "Standard for Static Inverters and Charge Controllers for Use in Photovoltaic Power Systems" for inverters, and IEEE 929 "Recommended Practice for Utility Interface of Photovoltaic (PV) Systems," for interconnection issues has been important in this progress. As inverter manufacturers resolve design and manufacturing issues and move toward implementing quality manufacturing processes such as ISO-9001, we are beginning to see significant improvement in inverter reliability.

Although maintenance should decrease as inverter reliability improves, some of the issues surrounding installation and maintenance of these systems will remain. As presently designed, trained technicians or electricians are required to install or maintain these systems, and the distributed nature of these small systems imposes a significant cost for travel. Projects with large numbers of co-located systems permit cost reduction strategies such as retaining trained service personnel, maintaining an inventory of parts to reduce downtime and multiple service calls, and permitting multiple systems to be serviced in a given trip. The cost differential between in- and out-of-warranty repair is significant, a factor of 2 or 3 . Inverter manufacturers are beginning to offer extended warranties for a fee. Long-term reliability data will be needed by both the manufacturers and project operators to set and evaluate these fees against alternative repair options.

Quantified data on the reliability and O\&M cost of residential and commercial systems is sparse. A review of 126 systems monitored by Ascension Technology ${ }^{5,6}$ between July 1994 and July 1997 found that $75 \%$ of the failures were due to inverters, with a mean time between failure (MTBF) of 1.65 years. O\&M cost data was not collected. Other problems were with disconnect switches due to blown dc fuses, source circuit protector boxes due mainly to failed blocking diodes, and array wiring. Module MTBF was 552 years, indicating module reliability is satisfactory. Note that this does not mean modules can be expected to last over 500 years, but rather that given 552 modules, one can be expected to fail in a given year. The 
MTBF value refers not to lifetime but to the failure rate during that portion of component life when failure rates are stable. At end of life, new failure mechanisms appear and the MTBF value is no longer valid. As a reference point, achieving $\$ 0.01 / \mathrm{kWh} O \& M$ costs on a $2 \mathrm{~kW}$ system with an inverter having an out-of-warranty repair cost of $\$ 500$ requires a 14-year inverter MTBF and no other failures or service.

More detailed information has been collected from SMUD's PV Pioneer residential and commercial grid-tied PV program. Results reported for a year of operation between 1996 and $1997^{6}$ on 332 systems in four program phases gave MTBF values between 7 and 16 years and in-warranty service costs to SMUD of between $\$ 0.004$ and $\$ 0.042 / \mathrm{kWh}$ with about $90 \%$ of the failures due to inverters. The mean time to repair (MTTR) these systems ranged from 3 to 9 months due in large part to the unavailability of a service technician. Data from the most recent year indicates there has been a significant reduction in the number of failures, by as much as half, which would drop SMUD's in-warranty service cost to about $\$ 0.01 / \mathrm{kWh}$ on the average over all the program phases. But exact quantification is impossible until the backlog in servicing is reduced, because up to half of the systems flagged as non-performing through meter reading are, in fact, operating. This non-steady, declining failure rate for existing systems indicates inverters in these systems are still in the range of one-time startup or infant mortality failures, and that they haven't reached a steady-state midlife failure rate. This supports assertions by a major inverter manufacturer that failures have been due to transportation-related component breakage, cooling system quality control, and control software issues, rather than component failures. ${ }^{4}$

Resolving this key issue of inverter reliability will require that inverter manufacturers complete implementation of their quality control programs. Reliability monitoring of systems with early-generation inverters and of newer systems with improved inverters should be continued to quantify and verify expected trends. As inverter issues are resolved, other issues will need further attention. These include long-term monitoring of these grid-tied systems to identify end-of-life failure mechanisms; monitoring new building-integrated designs to identify any new reliability issues; developing a better understanding of roof maintenance issues on system economics; and developing a better understanding of installation and service infrastructure program elements and their impact on reliability cost. The last issue requires consistent tracking of scheduled and unscheduled maintenance programs and costs, including labor and hardware costs. Further work is needed to reliably and cost-effectively identify failed or under-performing systems. Reliability data is needed on ac modules, which offer an alternative to the more traditional single inverter design. Although capital costs are presently higher, initial inverter reliability appears promising; and the installation and servicing infrastructure costs will most likely be lower.

\section{Status and Key Reliability Issues for Grid-tied Bulk Power Systems}

The functional requirement of bulk-power grid-tied PV systems is the same as that for smaller residential and commercial systems: to provide energy to the grid. But the siting (ground mounted) and scale (100kW to $5 \mathrm{MW}$ ) lead to different design and operational issues. Unlike small residential or commercial systems, which can sometimes take advantage of net metering to value the energy at the retail rate, these bulk power systems use a lower wholesale value, $\$ 0.02$ to $\$ 0.05 / \mathrm{kWh}$, for the energy produced. The systems can be owned by local utilities, or they can be owned by separate entities that sell energy to the utility. Target costs for O\&M from the PV portion of the system are generally on the order of $\$ 0.001 / \mathrm{kWh}$, one-tenth that 
used in the residential system analysis. Additional site O\&M issues such as taxes, security, and weed control add costs that must be considered as well. An O\&M cost of $\$ 0.001 / \mathrm{kWh}$ translates to an allowable system annual O\&M of $\$ 182$ to $\$ 9125$ for systems ranging from $100 \mathrm{~kW}$ to $5 \mathrm{MW}$. The economy of scale relative to residential systems is evident in reliability requirements. Even on a $200 \mathrm{~kW}$ system, a $\$ 1000$ repair requires only a 2.7 -year MTBF to achieve these smaller O\&M rates.

As with smaller grid-connected PV systems, bulk-power system design is well understood. Occasionally design issues arise that must be added to lessons learned. An example occurred in systems using welded intermodule wiring connections, which failed due to differential thermal expansion of the copper bus and plastic cover. ${ }^{8}$ Due to their larger size and ground mounting, tracking is used by almost all these systems to boost energy production. The basic north-south one-axis tracking flat plate design which dominates this application category was well studied over a decade ago., ${ }^{9,10}$ More recent efforts to optimize structure costs include design of the Delta Tracker by Ron Matlin for Advanced Photovoltaic Systems (APS) as a tracking version of APS's low-cost PVUSA support structure ${ }^{11}$, and development of Utility Power Group's (UPG, now part of Golden Genesis) tracker building block which eliminates machined bearings and uses a commercially-available screwjack. ${ }^{12}$

The main reliability issue for this application sector is operation of components, primarily the inverters and secondarily the trackers. PV module failure rates, on the other hand, are low, with an MTBF on the order of 6,666 years ( 1.5 failures per 10,000 per year). ${ }^{13}$ Highpower field level inverters offer economies of scale, but they have often been the key reliability issue for this application sector. Fortunately, as with residential systems, grid-tied inverter performance is improving. In the $1980 \mathrm{~s}$, two $60 \mathrm{~kW}$ inverters installed in the Lovington, New Mexico system exhibited availabilities of under 50\% leading to the system's being abandoned in place when O\&M costs exceeded system value. ${ }^{13}$ The two $1 \mathrm{MW}$ inverters installed at SMUD's PV1 and PV2 in 1984 and 1986 have required maintenance action about three times a month since 1993 according to site logs, mainly to reset the inverter for out-of-tolerance conditions or to replace blown fuses in the inverter bridge. ${ }^{14}$ Not all early inverters performed poorly. A $300 \mathrm{~kW}$ building integrated system at George Washington University in Washington, DC, has experienced few problems--even with the inverter--and is still operating. ${ }^{15}$ Inverter technology has advanced significantly since these early systems, improving the harmonics and power factor by replacing SCR power switches with high frequency IGBT switches. More recent inverter failures have been due to internal component failures and controller-induced shutdowns related to the dc or ac environment that were not properly understood. As these issues are being fixed, we are seeing instances of some inverters exhibiting low levels of required service. Two inverters, by Trace Technologies and Utility Power Group, are representative of more recent inverter capability. Trace Technologies, formerly Kenetech Windpower, has installed over 1000MW of inverters for wind, industrial drive, and battery storage applications. Much of the converter and control hardware for PV applications is identical to these applications, but control software must provide max power tracking and anti-islanding functions for PV applications. In four years, Trace Technologies has shipped 18 units between 20 and $300 \mathrm{~kW}$, totaling $2.4 \mathrm{MW}$. These have exhibited an MTBF of 1.57 years and an availability over $98 \%{ }^{16}$ UPG developed its own combined inverter/array tracking controller for use on its $14 \mathrm{~kW}$ one-axis tracking PV building block. With over 50 units installed, having accumulated over 43 years of operation, there has been no failure of the inverter and only one failure of the tracker due to a sticking relay. ${ }^{17}$ 
Array tracking is employed because it can increase system energy output by $20-25 \%$ annually while increasing system cost marginally. Experience with trackers has varied from excellent to poor, indicating the need to heed lessons learned. Trackers fall into three categories: passive, which use a thermally activated working fluid but no controls or electromechanical drives; sun sensing; and ephemeris (which computes the sun's position), both of the latter of which use electromechanical drives and control logic. Passive trackers built by Robbins Engineering were used on the Austin PV300 system, PVUSA's EMT-1 system, and on PG\&E's Kerman plant. Slow response, especially in cold weather, and lagging movement cause energy losses of $13 \%$ in summer to $25 \%$ in winter. ${ }^{18}$ Although availability was initially high (over $99 \%$ in the Austin PV300 system) after 5-6 years seal failures caused erratic performance. ${ }^{19}$ Active trackers have demonstrated mixed performance, with some systems requiring maintenance on actuators, controls, limit switches, relays, and wind stow sensors, and others performing well for over a decade. The 208 trackers in SMUD's PV1 and PV2 arrays are still tracking well 12 and 14 years after system startup, a period of 2700 trackeryears. O\&M has been minimal. Fewer than 3 or 4 tracker maintenance incidents were logged for each field since 1993, suggesting an MTBF on the order of hundreds of years. ${ }^{20}$ Tracking system maintenance varied from almost $\$ 0.02 / \mathrm{kWh}$ for the sun sensing system at Sky Harbor to $\$ 0.0002 / \mathrm{kWh}$ for the ephemeris controller at Carrisa Plains, indicating the low cost potential of a well implemented tracking system. ${ }^{21}$

Data from seven early systems gave an average O\&M cost of $\$ 0.04 / \mathrm{kWh}$ for plants installed prior to 1983 and $\$ 0.01 / \mathrm{kWh}$ for plants installed between 1983 and $1990 .^{21}$ The inverter accounted for about half the total. Four PVUSA utility-scale systems installed at Davis and Kerman incurred preventative maintenance costs between $\$ 0.001$ and $\$ 0.005 / \mathrm{kWh}$, mainly for inverter inspection and cleaning, and tracker inspection and lubrication. Failurerelated maintenance costs ranged between $\$ 0.004$ and $\$ 0.063 / \mathrm{kWh}$ over four years. ${ }^{22,23}$ Excluding inverter failure-related maintenance, the values drop to between $\$ 0$ and $\$ 0.004 / \mathrm{kWh}$, with most of the remaining failures coming from wiring, connection, and tracker issues. These results indicate that the knowledge exists to design and operate systems with the PV portion of O\&M expenses approaching the $\$ 0.001 / \mathrm{kWh}$ target if satisfactory inverter reliability is achieved and lessons learned from prior systems are applied to future operations (for example, employing a good design, good quality, appropriately sized components, and achieving quality installation.) As with smaller grid-tied systems, end-of-life failure mechanisms and longer-term capital replacement costs are not well characterized and require further research.

\section{Status and Key Reliability Issues for Grid-Independent Non-Hybrid Power Systems}

Grid-independent (stand-alone) PV systems that do not employ an alternative generator represent the largest application sector for PV. This is not because system costs are low, but because the value of the systems is high due to high avoided costs. Functional requirements vary, including supplying water, light, cathodic protection, telecommunication relay services, and the like, on a regular basis, despite variations in solar resource on a daily and seasonal basis. Avoided direct costs are high due to the high costs of providing power by line extension or diesel generators. Avoided indirect costs are also high and include loss of livestock from lack of water, loss of work and education opportunity from lack of evening light, loss of piping due to corrosion, etc. 
Several major potential markets exist for even larger growth of this sector. These include area lighting (where the cost of installing the light can be high due to trenching and wiring) and developing country village lighting and communication applications (which are often extremely remote so that engine maintenance is impractical but cost is critical). These applications are generally presently served by diesel gen-sets or pump-sets.

A 1993 estimate for fast food industry new installation parking lot lighting market alone was over 13,000 lights per year. ${ }^{24}$ The Solar Electric Light Company (SELCO) plans to install over a million village lighting systems in Vietnam during the next decade, consisting of a single PV panel and battery and two $8 \mathrm{~W}$ fluorescent lights. And it just received a loan to finance installation of the next phase of 12,000 solar home systems. ${ }^{25}$ SOLUZ has installed over 1,800 lighting systems in the Dominican Republic and Honduras since 1994. ${ }^{26}$ Recently Shell and the South African national utility announced they are partnering to install 50,000 solar home systems. The existing world market for diesel gen-sets was $1,903 \mathrm{MW}$ and for diesel pump-sets was $10,439 \mathrm{MW}$ in $1996{ }^{27}$ Over $80 \%$ of the generator sets, representing over $60 \%$ of the power, was for installations below $20 \mathrm{~kW}$. Over $55 \%$ of the pump-sets, representing over $30 \%$ of the power, was for installations below $20 \mathrm{~kW}$. Although the diesel infrastructure is well established and capital costs are low $(\$ 0.60 / \mathrm{W})$, the low-power end of these markets may represent an opportunity for low-maintenance PV.

Direct power systems, most often water pumping, use no electrical energy storage and are simpler to design and operate than systems employing batteries. The general design process is well understood: identify the load requirements, select an appropriate pump/motor set, and size the PV panel appropriately. Design options include using dc or dc brushless motors or using a variable frequency inverter with ac motors. Differences exist with initial cost, pump/motor replacement frequency, pump/motor availability, and efficiency. Ac pumps are a low-cost, mature, and widely used technology. PV systems have generally used dc pumps, which are custom developed for PV and, therefore, less widely available, to connect directly with the PV panels. Although dc pumps cost twice what ac pumps do, they don't require an inverter and they are significantly more efficient (roughly $85 \%$ vs. $62 \%$ ), allowing use of a smaller, cheaper PV array. Dc systems generally use solar trackers to boost PV panel current in the morning and evening to meet pump threshold levels, extending the daily operating period. Recently, a few companies have begun using variable-frequency ac motor drives powered by the dc panel. Little quantified reliability information that could be used to identify cost tradeoffs is available on any of these PV water pumping options. Probably the best data is from a 1992 survey conducted by EPRI of 154 customers with systems under five years old. ${ }^{28}$ Tracker and PV panel reliability were excellent. An average of one failure occurred per system; $63 \%$ of these were due to pump failures, mainly from defective parts and improper installation. MTBFs ranged from 1.4 to 5 years depending on pump type, and scheduled maintenance was required once or twice a year. Further information is needed on the reliability of different design options before requirements for improved reliability can be identified or optimal design configurations can be determined.

In order for systems incorporating battery storage to achieve their potential market penetration, their design and integration must be of high quality so that they can reliably achieve the user's functional requirements. Battery cost, both initial and replacement, are a major factor in these systems. Battery performance (cycle-life and capacity), which determines replacement frequency, in deep-cycle, resource-constrained charging environments, is poorly characterized. Design tradeoffs for these systems, unlike those for previously discussed systems, are poorly quantified. There are many design factors, and they are intricately interrelated. Even vandalism mitigation efforts, often important for these 
remote systems, can significantly impact system performance. A quantified understanding of these relationships is needed to optimize the wide range of design options trading-off initial battery capital cost (which depends on battery type and size), battery capital replacement cost (which depends on battery cycle life), and O\&M cost (which depends on battery type and labor costs). Performance of batteries in these systems is very sensitive to sizing of the battery and array. Additionally, the cost and infrastructure characteristics of maintenance at the site are critical design inputs that impact many of the design decisions. These sitedependent factors in the design, furthermore, lead one toward customized systems rather than standardized ones that permit improved reliability through design maturity and familiarity by the installer/servicer. Much of the needed performance information is anecdotal; and the controlled studies that have been done cannot cover all the potential design variations or the local variations in resource and load to which the system performance is often very sensitive. A brief summary of the major issues and status of knowledge is presented.

Proper sizing of the battery and array to the load is essential for system reliability. One step in the design sequence requires establishing the ratio of PV array energy output to system load. The array is then sized so the lowest monthly array-to-load ratio is never less than the established value. When establishing the design array-to-load ratio, all system losses should be considered. One such loss is battery charging loss, which leads to the need for what is often called battery overcharge. This battery overcharge is a measure of the extra energy put in to the battery during charging which goes to overcoming internal battery losses. Battery charging losses are minimal at intermediate states of charge (SOC) but increase dramatically near $100 \%$ SOC. In flooded batteries, incremental charge efficiency can drop to the $70 \%$ range at $80 \%$ SOC, and well below $50 \%$ as SOC approaches $100 \%{ }^{29}$ This has implications for systems with very shallow depths of discharge (DoD) because the average cycle efficiency is lower than for a system with a larger DoD. Studies have shown that a minimum worstmonth array-to-load ratio of 1.25 to 1.3 is needed to achieve a full SOC when cycling between 0 and $30 \%$ DoD. $^{30}$ If the solar resource doesn't match the charging profile of the battery, an even higher ratio may be needed. Array-to-load ratios as high as 2:1 are often recommended for critical loads. Valve-regulated lead acid (VRLA) batteries, including gel and absorbed glass mat (AGM) designs, have higher charge efficiencies than flooded batteries, but they take longer at regulation voltage to accept the charge. The resulting required array-to-load energy ratio is about the same as for flooded batteries to achieve a high SOC because the solar resource doesn't match the charging profile of the battery. It has not been uncommon for systems to be sized without regard for these losses. Systems sized without a good understanding of these losses often have worst-month array-to-load ratios of 1.0 to 1.1 , leading to incomplete charging during those months, significantly impacting battery cycle life.

Battery charging losses can also be greatly affected by charge controller type and setpoints. Studies have shown that factory recommended charge controller setpoints are often too low to effectively couple PV energy to batteries during the short charging periods the solar resource is available, but raising the setpoints often increases water loss and maintenance requirements in flooded batteries. ${ }^{30,31}$ One study showed low setpoints wasted $90 \%$ of array energy, causing battery undercharge and reduced cycle life. ${ }^{32}$ Another showed that low setpoints caused a $40 \%$ loss of battery capacity in three months. ${ }^{33}$ With proper setpoints, however, both constant voltage and on/off controllers can provide almost identical overcharge and water loss performance. ${ }^{33}$ Catalytic recombination caps have been shown to double or triple the service interval of flooded lead-acid batteries by reducing electrolyte loss. When these caps are used on flooded lead-antimony batteries that have been manufactured to 
provide additional electrolyte space above the plates, these batteries can compete with the low maintenance requirements of VRLA batteries in stand-alone PV systems. ${ }^{33}$

Battery sizing in non-hybrid PV applications depends on the number of sequential days of cloudiness the system is designed for, the maximum charge rate of the PV array, and the low voltage disconnect value used. Although manufacturers publish curves showing battery cycle life vs. DoD, a better understanding is needed of the impact extended reduced SOC on battery life, including the impact of the amount of time spent at the reduced SOC. For very small systems, the U. S. Coast Guard has been successful operating systems with no charge controller at very low (below 1) worst-month array-to-load ratios by using low voltage, selfregulating panels and batteries that are very large relative to the load. This keeps the battery at a low state of charge for months, but service lives up to six years have been achieved using oversized sealed lead-acid batteries. ${ }^{34}$ Shallow discharge starting, lighting, and ignition (SLI automotive) lead antimony batteries, which are often used in developing countries due to availability, frequently operate at a low SOC and often last 18 months. Good information on their service lives is needed.

Increasing availability and use of listed components and standardized component packages has improved system reliability. Still, reliability is an issue with some components, especially with battery charge controllers. Anecdotal information exists of excessive out-ofthe-box and premature charge controller failures, but little quantified data exists correlating controller MTBF with quality and cost. Over a three-year period in 70 systems installed in the Colorado State Parks, both on/off and constant voltage charge controllers experienced MTBFs of between 15 and 18 years. ${ }^{35}$ Quality and reliability of dc lamps and ballasts for PV lighting systems has also been an issue. Low pressure sodium (LPS) lamp output decreased $20 \%$ and load current increased $40 \%$ over seven months in a test of 15 lighting systems. ${ }^{36}$ Poor quality and low efficiency dc ballasts have caused premature LPS and compact fluorescent lamp failures in other projects. ${ }^{24,31,37}$

Knowledge of the installation and maintenance environment for a system is critical for design, installation, and operation of a sustainable system involving battery storage. Maintenance is essential for these systems; and if the design makes maintenance difficult or if funding for maintenance evaporates with the departure of a system champion, the maintenance often won't get done and the system generally does not survive. Valuable lessons have been learned in a number of projects, but little quantified data exists on the cost and effectiveness of different service infrastructures. For cost reasons systems are often maintained by local facility staff, but this requires a simple, standardized, well-marked design that is easy to install, test, and service. ${ }^{24,35,38}$ Maintenance costs of 70 dc lighting systems operated over three years in the Colorado State Parks system were about $\$ 100$ per year in hardware (roughly $8 \%$ of the initial hardware cost) and three hours per system in labor. Scheduled maintenance took 20 minutes semi-annually; and about $60 \%$ of hardware costs and $50 \%$ of labor was to repair vandalized systems. This does not include battery replacement costs, which are expected after the fourth year. Remote solar home system projects, both domestically and internationally, generally use trained personnel to service systems, and have to train users against over-depletion of the battery or even lock the battery case to prevent abuse. $^{26,37}$ Success of these systems depends on implementing a servicing program covering routine and unscheduled maintenance using trained local technicians. Costs for servicing 72 systems in the dispersed Navajo Tribal Utility Authority (NTUA) region were high, between $\$ 1500$ and $\$ 1900$ per system annually. The system MTBF was 1.2 years. This was due in part to the lack of a scheduled maintenance program, lack of training for users, and long 
service distances averaging 170 miles, as a result of having only one centrally-located, trained technician. ${ }^{39}$

The reliability and cost of stand-alone non-hybrid systems depend largely on robust system design and a service program appropriate for the local infrastructure. Lessons from many existing programs and systems need to be incorporated into the development of future systems. Additionally, a better understanding and quantification is needed of the interrelated design issues and servicing programs.

\section{Status and Key Reliability Issues for Grid-Independent Hybrid Power Systems}

Hybrid power systems incorporate photovoltaic panels and batteries, but they are fundamentally different than non-hybrid systems in that there is an alternative source of power, generally an engine-generator, that can service the load and charge the batteries. Adding batteries to a generator/load design can increase generator efficiency dramatically if the load is highly variable, because the engine running at full load is more efficient by a factor of up to 5 or 6 than one running at fractional load. When the batteries discharge, the generator recharges them, operating a large part of the time at its most efficient operating point and part of the time at a less efficient point as the battery charge current tapers during the finish-charge. In addition to the generator efficiency losses, there are battery efficiency losses that are about $30 \%$ for vented (flooded) batteries and about 10\% for VRLA batteries.

Adding photovoltaic power complicates the design optimization process due to the time dependency of the solar resource and the added complexity on the energy management control system. Although the value of the system energy is high for the same reasons as nonhybrid systems, PV energy now must compete with that from the generator operating at full load efficiency. The optimal operational strategy to make best use of PV energy has not been well investigated in hybrid systems, and it is not easy to accomplish without "smart" control logic. A strategy is needed for generator operation to best use time-constrained PV energy and to fulfill lengthy battery charge requirements while minimizing starts and stops which stress the generator. The inverter control system must handle rapid changes in direction of energy transfer between the two energy sources, the battery, and the load, which often includes complex non-resistive components.

Although much progress is being made in these controls, experience is still that multiple service calls are needed to field-tune the system to match the controls with the generator and the load during transfer from dc (battery/PV) to ac (generator) energy source under complex load conditions. Additionally, hybrid inverters need improved tolerance to transients.

Limited data exists on the reliability and life cycle costs of hybrid systems. Because multiple generators exist in these systems, reliability and availability are generally high. Results from three hybrid systems ${ }^{40}$ showed all systems were very reliable, with availabilities over $99 \%$ on two systems. Cost comparisons showed the hybrid systems were slightly less expensive on a life-cycle basis than generator-only options. Important to achieving these results were the efforts to reduce the overall electrical load by using standard energy efficiency measures. Assumptions regarding battery life and replacement will need to be verified by operating experience. 


\section{Conclusions}

The systems-level approach presented here for understanding PV reliability and optimizing design and operation is essential for achieving sustainable systems. Presently reliability data is limited and anecdotal in certain core elements including design, component reliability, installation, and maintenance of the different PV application sectors. Existing PV projects offer significant lessons learned that can greatly improve PV reliability if they are applied to future systems. However, limited data exists concerning the contribution of reliability costs to the overall system cost, and there is a limited understanding of how to best trade-off different avenues to achieving system reliability. Further work in these areas is essential to ensure we have the knowledge to quantify and predict system reliability and enable photovoltaic systems to achieve their full potential.

\section{References}

1. Final Report: Workshop on PV Program Strategic Directions, National Center for Photovoltaics, Denver, Colorado, July 14-15, 1997.

2. T. Lepley and P. Nath, "Photovoltaic Covered-Parking Systems Using Lightweight, ThinFilm PV," Proceedings of the $26^{\text {th }}$ IEEE Photovoltaic Specialists Conference, Anaheim California, September 29-October 3, 1997.

3. B. H. Chowdhury et. al, "A 50kW Distributed Grid-Connected Photovoltaic Generation System for the University of Wyoming," Proceedings of the $26^{\text {th }}$ IEEE Photovoltaic Specialists Conference, Anaheim California, September 29-October 3, 1997.

4. Dale R. Stefanac, "Process Quality in Manufacturing PV Power Conversion Products," Proceedings of the 1998 Photovoltaic Performance and Reliability Workshop, Cocoa Beach, Florida, November 3-5, 1998.

5. Miles Russell, "Frequency of Problems in Over 100 Grid-Tied PV Systems," presented at the 1997 Photovoltaic Performance and Reliability Workshop, Las Cruces, New Mexico, August 5-6, 1997.

6. A. Maish, et. al., "Photovoltaic System Reliability," Proceedings of the $26^{\text {th }}$ IEEE Photovoltaic Specialists Conference, Anaheim California, September 29-October 3, 1997.

7. Edward C. Kern, Jr. "Will AC Modules Reduce System Lifecycle Costs?", Proceedings of the 1998 Photovoltaic Performance and Reliability Workshop, Cocoa Beach, Florida, November 3-5, 1998.

8. J. Hoffner, The Utility Experience Base with PV Systems, Utility Photovoltaic Group, June 1994. 
9. G. T. Noel and R. W. Smith, Central Station Photovoltaic Array-Field Designs and Design Practices, SAND87-7003, March 1987, Albuquerque, New Mexico. (Work performed by Battelle).

10. J. A. Castle, Modular Array Field Designs for Tracking Flat-Plate Photovoltaic Systems, SAND86-7036, June 1987, Albuquerque, New Mexico. (Work performed by Hughes Aircraft Company).

11. D. S. Shugar, and R. W. Matlin, "Design and Prototype of a Minimal Cost Tracking Photovoltaic Array Structure," Proceedings of the American Solar Energy Society Conferenc, e Solar 95, Minneapolis, Minnesota, July 1995.

12. M. Stern and R. West, "Development of a Low Cost Integrated 15kW AC Solar Tracking Subarray for Grid Connected PV Power System Applications," Proceedings of the $25^{\text {th }}$ IEEE Photovoltaic Specialists Conference, Washington, DC, May 1996.

13. S. J. Durand, "Attaining a 30-Year Photovoltaic System Lifetime: the BOS Issues," Progress in Photovoltaics: Research and Applications, Vol. 2, 107-113 (1994).

14. Southwest Technology Development Institute, Test Report: Sacramento Municipal Utility District Photovoltaic Systems at Rancho Seco and the Hedge Site, (Draft report to Sandia National Laboratories of testing performed August 17-20, 1998 under contract AV-5589).

15. Southwest Technology Development Institute, Maintaining Large Photovoltaic Power Systems, Concepts and Costs, (Draft report to Sandia National Laboratories, September 1998).

16. Personal Communication, M. Behnke, Trace Technologies, May 29, 1998.

17. Personal Communication, G. Forier, Utility Photovoltaic Group, October 23, 1998.

18. T. Townsend and C. Whitaker, "Measured vs. Ideal Insolation on PV Structures," Proceedings of the $26^{\text {th }}$ IEEE Photovoltaic Specialists Conference, Anaheim California, September 29-October 3, 1997.

19. PVUSA Quarterly Technical Report, First Quarter 1997, Sacramento Municipal Utility District, December, 1997.

20. Personal Site Notes, August 17, 1998.

21. K. Conover, "Photovoltaic Operation and Maintenance Evaluation," Proceedings, IEEE Power Engineering Society Winter Meeting, February 1990.

22. C. Jennings, et al., "PVUSA - The First Decade of Experience," Proceedings of the $25^{\text {th }}$ IEEE Photovoltaic Specialists Conference, Washington, DC, May 13-17, 1996. 
23. C. Jennings, A. Reyes, and K. O'Brien, "PVUSA Utility-Scale System Capital and Maintenance Costs," Proceedings of the First World Conference on Photovoltaic Energy Conversion, Waikoloa, Hawaii, December 1994.

24. Karen Miller, Photovoltaic Parking Lot Lighting Systems, an Evaluation for Use in a Fast Food Application, (Draft Final Report), University of Florida Energy Extension Service, 1994.

25. Photovoltaic News, October 1998.

26. J. Rogers, "Mining the Data: Learning Reliability Lessons from PV Leasing," Proceedings of the 1998 Photovoltaic Performance and Reliability Workshop, Cocoa Beach, Florida, November 3-5, 1998.

27. R. Hammond and K. Whitfield, "Worldwide Production and Consumption of Diesel Engines," Solar Industry Journal, Volume 9, No. 1, 24-32.

28. K. Stokes and J. Bigger, "Reliability, Cost and Performance of PV-Powered Water Pumping Systems: A Survey for Electric Utilities," Proceedings of the IEEE Power Engineering Society 1992 Summer Meeting, Seattle Washington, July 12-16, 1992. [Also published in Proceedings of the 1992 Photovoltaic Performance and Reliability Workshop, Golden, Colorado, September 16-18, 1992].

29. J. W. Stevens and G. P. Corey, "A Study of Lead-Acid Battery Efficiency Near Top-ofCharge and the Impact on PV System Design," Proceedings of the 25th IEEE Photovoltaic Specialists Conference, Washington, DC, May 1996.

30. J. R. Woodworth, et al., Evaluation of the Batteries and Charge Controllers in Small Stand-alone Photovoltaic Systems, First WCPEC, Hawaii, 933-945, December 1994.

31. S. Harrington and T. Hund, "Photovoltaic Lighting System Performance," Proceedings of the $25^{\text {th }}$ IEEE Photovoltaic Specialists Conference, Washington, DC, May 1996.

32. J. Stevens, "Energy Utilization in PV Systems," Proceedings of the Photovoltaic Performance and Reliability Workshop, Lakewood, Colorado, September 4-6, 1996.

33. J. Dunlop, Venice Photovoltaic Lighting Systems Evaluation Report, Florida Solar Energy Center, January 1997.

34. V. Alminauskas, "Performance Evaluation of Lead Acid Batteries for Use with Solar Panels," Proceedings of the 23rd IEEE Photovoltaic Specialists Conference, May 1993.

35. C. Dunn, Small Photovoltaic Systems in Colorado State Parks, (Final report for contract AV-1172, internal distribution).

36. J. Dunlop, Photovoltaic Lighting Systems for Brevard Community College's COMET Walkway, Florida Solar Energy Center, September 1997. 
37. Private Communication, B. Cook, Solar Electric Light Company, October 7, 1998.

38. T. Duncan, "Designing Systems for Performance and Reliability," Proceedings of the 1998 Photovoltaic Performance and Reliability Workshop, Cocoa Beach, Florida, November 3-5, 1998.

39. Program Summary Report for The Navajo Tribal Utility Authority Pilot PV Service Program, NEOS Corporation, February 1998.

40. A. Rosenthal, S. Durand, M. Thomas, and H. Post, "Economics and Performance of PV Hybrid Power Systems: Three Case Studies," Proceedings of the 1998 Annual American Solar Energy Society Conference, Albuquerque, New Mexico, June 1998. 